\title{
Transforming growth factor $\beta 1$ promotes migration and invasion in HepG2 cells: Epithelial-to-mesenchymal transition via JAK/STAT3 signaling
}

\author{
XIAO-LONG LIN ${ }^{1 *}$, MIHUA LIU ${ }^{2 *}$, YUANBO LIU ${ }^{3 *}$, HUIJUN HU $^{1}$, YONGQUAN PAN ${ }^{1}$, \\ WEIWEN ZOU ${ }^{1}$, XIAOJUAN FAN ${ }^{1}$ and XUEMEI HU ${ }^{1}$ \\ ${ }^{1}$ Department of Pathology, Huizhou Third People's Hospital, Guangzhou Medical University, Huizhou, Guangdong 516002; \\ ${ }^{2}$ Department of Clinical Laboratory, Affiliated Nanhua Hospital, University of South China, Hengyang, Hunan 421001; \\ ${ }^{3}$ Department of Neurology, The Sixth People's Hospital of Huizhou, \\ Huizhou, Guangdong 516211, P.R. China
}

Received June 1, 2016; Accepted October 25, 2017

DOI: $10.3892 /$ ijmm.2017.3228

\begin{abstract}
Transforming growth factor $\beta 1$ (TGF $\beta 1)$ is a cytokine with multiple functions. TGF $\beta 1$ significantly induces migration and invasion of liver cancer cells. However, the molecular mechanisms underlying this effect remain unclear. Epithelial-to-mesenchymal transition (EMT) is crucial for the development of invasion and metastasis in human cancers. The aim of the present study was to determine whether TGF $\beta 1$-induced EMT promoted migration and invasion in HepG2 cells. The underlying mechanism and the effect of EMT on HepG2 cells were also investigated. The results demonstrated that TGF $\beta 1$ may induce EMT to promote migration and invasion of HepG2 cells, and this effect depends on activation of the Janus kinase/signal transducer and activator of transcription 3 (JAK/STAT3) signaling pathway. JAK/STAT3 signaling is involved in human malignancies, including lung cancer, and is implicated in cell transformation, tumorigenicity, EMT and metastasis. In the present study, TGF $\beta 1$ also activated JAK/STAT3 signaling in HepG2 cells and promoted Twist expression, but these events were abolished by treatment with the STAT3 inhibitor AG490. Additionally, Twist siRNA blocked TGF $\beta 1$-induced EMT. Thus, TGF $\beta 1$ was shown to induce EMT, thereby promoting the migration and invasion of HepG2 cells via JAK/STAT3/Twist signaling.
\end{abstract}

Correspondence to: Mr. Xiao-Long Lin, Department of Pathology, Huizhou Third People's Hospital, Guangzhou Medical University, 1 Xuebei Street, Huizhou, Guangdong 516002, P.R. China

E-mail: 493814078@qq.com

${ }^{*}$ Contributed eually

Key words: epithelial-to-mesenchymal transition, transforming growth factor $\beta 1$, signal transducer and activator of transcription 3

\section{Introduction}

Liver cancer is one of the most common malignant tumors worldwide, and its incidence is the second highest in China. Liver cancer cannot be easily detected at an early stage due to the lack of distinct symptoms and the scarcity of clinically specific markers for serodiagnosis. Therefore, the majority of the patients are diagnosed at advanced or late stages, resulting in distant metastasis and a low 5-year survival rate (1). Thus, the metastasis and invasion of liver cancer must be clinically investigated to prevent progression of this disease and improve its prognosis.

The invasion and metastasis of malignant tumors are regulated and controlled by various factors and mechanisms. Epithelial-to-mesenchymal transition (EMT) is a key mechanism participating in the invasion and metastasis of solid cancers, such as colon, lung and pancreatic cancer (2-4). However, the association between EMT and the onset and progression of liver cancer has not been fully elucidated. In this context, Lee et al (5) and Giannelli et al (6) previously reported that EMT is involved in the invasion and metastasis of liver cancer cells.

A number of studies reported that transforming growth factor $\beta 1$ (TGF $\beta 1)$ is a cytokine with multiple functions that promotes EMT $(7,8)$. The activation abnormalities in the signal transducer and activator of transcription 3 (STAT3) signaling pathway are associated with tumor onset and progression (9). The activation of this pathway is regulated and controlled by the upstream factor Janus kinase (JAK). The activation of JAK/STAT3 signaling may directly affects EMT and promotes the invasion and metastasis of tumor cells in lung cancer and ovarian tumors (10). However, whether the EMT mediated by the JAK/STAT3 signaling pathway promotes TGF $\beta 1$-induced invasion and metastasis of liver cancer cells has not been clearly determined.

The present study investigated the human liver cancer line HepG2, in which invasion and metastasis were induced by TGF $\beta 1$. The role of JAK/STAT3 signaling in mediating the involvement of EMT in the invasion and metastasis of HepG2 
cells induced by TGF $\beta 1$ was also determined. Experiments were performed to confirm whether Twist is a target of STAT3. Overall, the aim of this study was to provide new experimental evidence and potential targets for preventing the invasion and metastasis of liver cancer cells.

\section{Materials and methods}

Cell culture. The liver cancer cell line HepG2 was purchased from Shanghai Institute of Biochemistry and Cell Biology, Chinese Academy of Sciences (Shanghai, China). HepG2 cells were cultured in Dulbecco's modified Eagle's medium (DMEM)-high glucose containing trypsin (cat no. SH30022.01B) supplemented with $10 \%$ fetal bovine serum (FBS; cat no. SH30084.03) (both from HyClone, Logan, UT, USA ), $100 \mathrm{U} / \mathrm{ml}$ penicillin (cat no. ST488-1; Beyotime Institute of Biotechnology, Shanghai, China) and $100 \mathrm{U} / \mathrm{ml}$ streptomycin (cat no. ST488-2; Beyotime Institute of Biotechnology) at $37^{\circ} \mathrm{C}$ under $95 \%$ air and $5 \% \mathrm{CO}_{2}$.

Reverse transcription-quantitative polymerase chain reaction (RT-qPCR). RNA was extracted from the tissue samples using TRIzol ${ }^{\circledR}$ reagent (Thermo Fisher Scientific, Waltham, MA, USA), according to the manufacturer's instructions. Subsequently, cDNA was synthesized using a TaqMan Reverse Transcription Reagents kit(ThermoFisher Scientific), according to the manufacturer's protocol. The relative expression levels of mRNA were determined using a Power SYBR-Green PCR Master Mix kit (Thermo Fisher Scientific) and normalized to GAPDH.RT-PCR was performed using the Applied Biosystems 7500 Fast Dx Real-Time PCR instrument (cat no. 4425757; Thermo Fisher Scientific) and the following gene-specific primers (Sangon Biotech Co., Ltd., Shanghai, China): GAPDH: Sense, 5'-TGCCATCAACGACCCCTTCA-3' and antisense, 5'-TGACCTTGCCCACAGCCTTG-3'; E-cadherin: Sense, 5'-AGCTATCCTTGCACCTCAGC-3' and antisense, 5'-CCCAGGAGTTTGAG-3'; N-cadherin: Sense, 5'-TCCTGCTCACCACCACTACTT-3' and antisense, 5'-CTGACAATGACCCCACAGC-3'; Smad: Sense, 5'-ATAAGCAACCGCCTGAACAT-3' and antisense, 5'-TTACCTGCCTCCTGAAGACC-3'; Twist: Sense, 5'-GCTGATTGGCACGACCTCT-3' and antisense, 5'-CACCATCCTCACACCTCTGC-3'; and vimentin: Sense, 5'-CCAAACTTTTCCTCCCTGAACC-3' and antisense, 5'-GTGATGCTGAGAAGTTTCGTTGA-3'. A control siRNA specific for the red fluorescent protein, 5'-CCACTACCTGAGCACCCAG-3', was used as the negative control (sc-37007; Santa Cruz Biotechnology, Inc., Santa Cruz, CA, USA). All primers were designed using the National Center for Biotechnology Information Primer-BLAST tool (http://www.ncbi.nlm.nih.gov/tools/primer-blast/). PCR was performed under the following conditions: Denaturation at $50^{\circ} \mathrm{C}$ for $2 \mathrm{~min}$, followed by 38 cycles at $95^{\circ} \mathrm{C}$ for $15 \mathrm{sec}$ and $60^{\circ} \mathrm{C}$ for $1 \mathrm{~min}$. Gene expression was normalized to internal controls and fold changes were calculated using the relative quantification method $\left(2^{-\Delta \Delta \mathrm{Cq}}\right)$ (11).

Western blot analysis. Cells were washed 3 times with ice-cold PBS and then incubated on ice with $250 \mu 1$ RIPA buffer (cat no. P0013; Beyotime Institute of Biotechnology) with $2.5 \mu \mathrm{l}$ phenylmethylsulfonyl fluoride (cat no. ST506-2; Beyotime Institute of Biotechnology ) for 15-30 min. The cells were collected and centrifuged at $13,000 \mathrm{xg}$ for $10 \mathrm{~min}$ at $4^{\circ} \mathrm{C}$. The protein concentrations of the cell lysates were measured in duplicate using a bicinchoninic acid protein assay kit (cat no. 23227; Thermo Fisher Scientific). The protein lysates and 6X loading buffer were mixed at a ratio of 4:1 and then boiled for $5 \mathrm{~min}$ at $100^{\circ} \mathrm{C}$. Equal amounts of total protein were separated by $10 \%$ sodium dodecyl sulphate-polyacrylamide gel electrophoresis and transferred onto polyvinylidene difluoride membranes (cat no. FFP39; Beyotime Institute of Biotechnology). The membranes were immunoblotted with monoclonal mouse $\beta$-actin $(1: 1,000$; cat. no. sc- 8432$)$, goat anti-human p-STAT3 (1:1,000; cat. no. sc-21876), monoclonal mouse anti-human JAK (1:400; cat. no. sc-376996), monoclonal mouse anti-human STAT3 (1:400; cat no. sc-293151), p-JAK (1:400; cat. no. sc-16773), E-cadherin (1:500; cat. no. sc-21791), N-cadherin (1:400; cat. no. sc-393933) and vimentin (1:400; cat. no. sc-373717) antibodies (all from Santa Cruz Biotechnology, Inc.) at $4^{\circ} \mathrm{C}$ overnight. All antibodies were diluted with $0.5 \%$ bovine serum albumin. Following incubation, the corresponding secondary antibody conjugated with peroxidase and enhanced chemiluminescence reagents (Beyo ECL Plus; cat. no. P0018; Beyotime Institute of Biotechnology) were applied, and the blot was visualized (cat. no. 121-2550; Beijing Liuyi Biotechnology Co., Ltd., Beijing, China). The amount of total protein was semiquantified as ratio to $\beta$-actin on each gel.

Scattering assay. Scattering assay was performed as previously described (7). HepG2 cells $\left(3 \times 10^{5} / \mathrm{ml}\right)$ were seeded into each well of a 24-well plate (cat. no. 662102; Greiner Bio-One $\mathrm{GmbH}$, Frickenhausen, Germany), and incubated overnight at $37^{\circ} \mathrm{C}$ in an atmosphere of $5 \% \mathrm{CO}_{2}$. The cells were pretreated with $10 \mu \mathrm{M}$ TGF $\beta 1$ for $48 \mathrm{~h}$ at $37^{\circ} \mathrm{C}$ for $48 \mathrm{~h}$ in $95 \%$ air and $5 \% \mathrm{CO}_{2}$. Representative images were captured at a magnification of $\mathrm{x} 20$ using the Eclipse TE2000-U inverted microscope (Nikon Corporation, Tokyo, Japan).

Invasion and migration assay. The invasion assay was performed using Transwell 24-well plates with $8-\mu \mathrm{m}$ pore polycarbonate membranes (BD Biosciences, Franklin Lakes, NJ, USA). Briefly, the upper side of the membranes was coated with Matrigel $(20 \mu \mathrm{g} / \mathrm{well})$ and the membranes were then air-dried for $1 \mathrm{~h}$ at $37^{\circ} \mathrm{C}$. The lower side of the membranes was coated with $5 \mu \mathrm{g}$ fibronectin, and the treated or untreated HepG2 cells $\left(2 \times 10^{5}\right)$ in $200 \mu 1$ of DMEM medium with $2.5 \%$ FBS were placed in the upper chamber. The lower chamber was filled with DMEM medium with 10\% FBS as the chemoattractant. The invasion chamber was incubated for $8 \mathrm{~h}$ at $37^{\circ} \mathrm{C}$ and $5 \% \mathrm{CO}_{2}$. The cells on the upper surface of the membrane were removed by gentle scrubbing with a cotton swab. The membranes were fixed in a stationary liquid of $95 \%$ ethanol and 5\% acetic acid for $30 \mathrm{~min}$ and stained with crystal violet. The number of cells on the lower surface of the membrane in 5 random visual fields (magnification, $\mathrm{x} 200$ ) was then counted using an Eclipse TE2000-U inverted microscope. Each assay was performed in triplicate.

Wound healing assay. The wound healing assay was performed as previously described: HepG2 cells $\left(3 \times 10^{5} / \mathrm{ml}\right)$ were seeded 

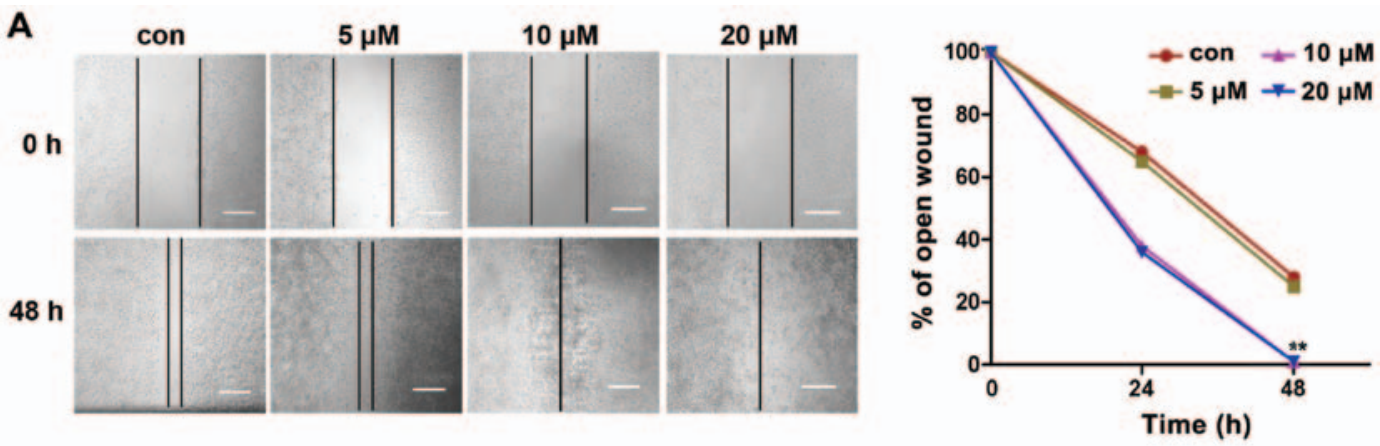

B
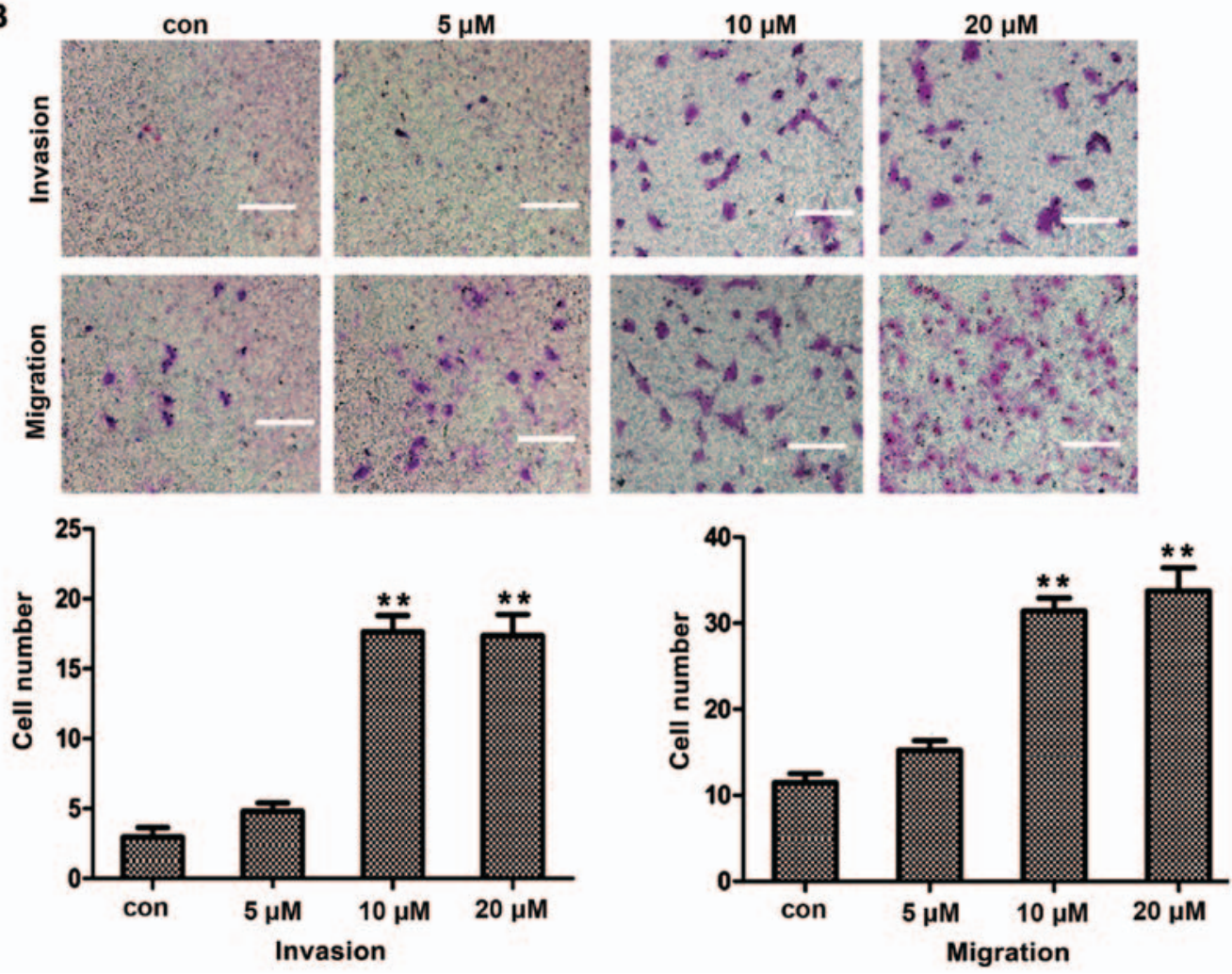

Figure 1. Migration and invasion induced by TGF $\beta 1$ in HepG2 cells. (A) In wound-healing assay, HepG2 cells were treated with TGF $\beta 1$ at different concentrations $(5,10$ and $20 \mu \mathrm{M})$ for $48 \mathrm{~h}$, and TGF 1 -induced cell motility was determined by measuring wound closure at a magnification of x 200 with Image-Pro ${ }^{\circledast}$ Express software. Scale bar, $10 \mu \mathrm{m}$. (B) For the migration and invasion assays, HepG2 cells were treated with TGF $\beta 1$ at different concentrations $(5,10$ and $20 \mu \mathrm{M})$ for $48 \mathrm{~h}$, and the cells were visualized by staining with toluidine blue and counted in 6 random high-power fields at a magnification of x200 using Image-Pro ${ }^{\circledast}$ Express software. Scale bar, $5 \mu \mathrm{m}$. The experiments were performed in triplicate. Data are presented as mean \pm standard deviation. ${ }^{* *} \mathrm{P}<0.01$ vs. control group. TGF $\beta 1$, transforming growth factor $\beta 1$; con, control.

into a 6-well plate (cat. no. 657160; Greiner Bio-One $\mathrm{GmbH}$ ) in serum-containing medium, and incubated at $37^{\circ} \mathrm{C}$ in an atmosphere of $5 \% \mathrm{CO}_{2}$ in order to form a confluent monolayer. The monolayer was scratched using a sterile plastic pipette tip (cat. no. CLS4860; Sigma-Aldrich, Merck KGaA, St. Louis, MO, USA), and washed with PBS to remove cell debris. Subsequently, fresh medium was added, and $10 \mu \mathrm{M}$ TGF $\beta 1$ or $0.1 \mathrm{ml}$ DMSO was added to each well. The scratched monolayer was incubated at $37^{\circ} \mathrm{C}$ in an atmosphere of $5 \% \mathrm{CO}_{2}$ for $48 \mathrm{~h}$. Wound closure was measured in 6 random high-power fields at a magnification of x200, using Image-Pro ${ }^{\circledR}$ Express software, version 6 (Media Cybernetics, Inc., Rockville, MD, USA) and an Eclipse TE2000-U inverted microscope (11).

Statistical analysis. Data were analyzed using SPSS software, version 1.0 (SPSS, Inc., Chicago, IL, USA) and GraphPad
Prism software, version 5.0 (GraphPad Software, Inc., La Jolla, CA, USA). Analysis of variance was conducted followed by the Student's t-test. The data are presented as mean \pm standard deviation. $\mathrm{P}<0.05$ was considered to indicate statistically significant differences.

\section{Results}

TGF $\beta 1$ induces migration and invasion of HepG2 cells. To determine the migration and invasion induced by TGF $\beta 1$, liver cancer HepG2 cells were treated with different concentrations of TGF $\beta 1$ for $48 \mathrm{~h}$, and the migration and invasion of cancer cells were assessed by wound closure assays and Matrigel Transwell chamber invasion assays. The effects of TGF $\beta 1$ were observed at concentrations as low as $5 \mu \mathrm{M}$. As the TGF $\beta 1$ concentration increased, the migration and invasion of HepG2 
A

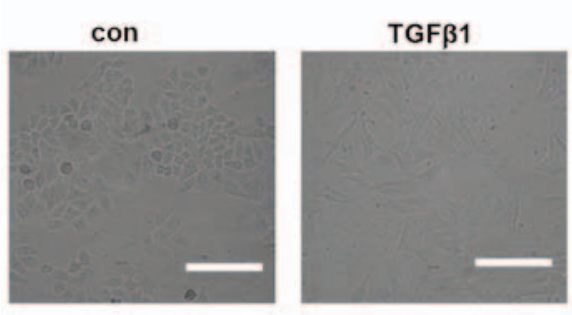

C

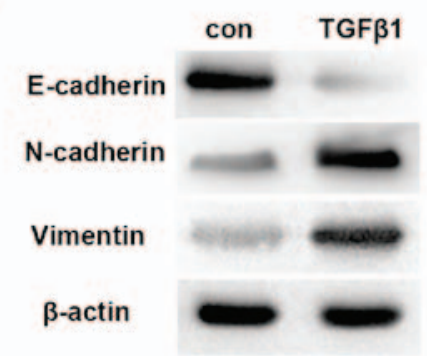

E

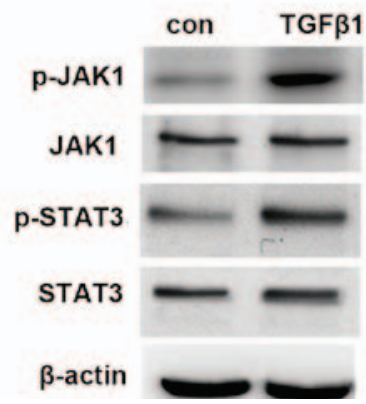

B

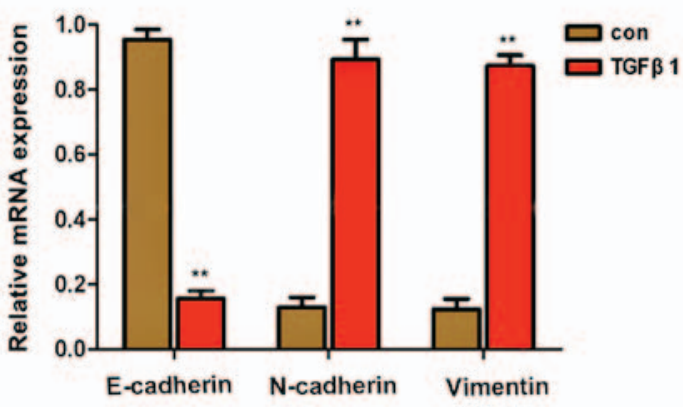

D

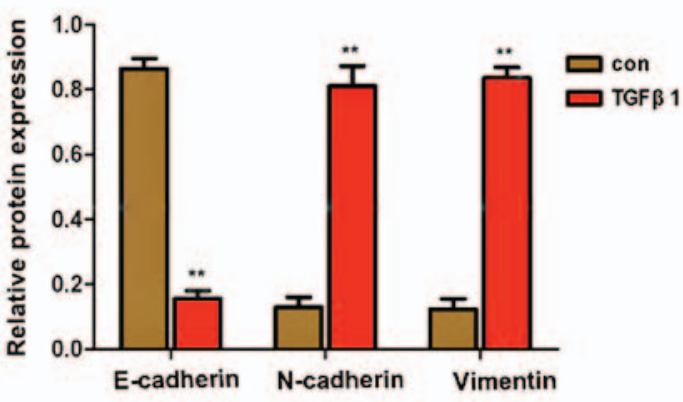

$\mathbf{F}$

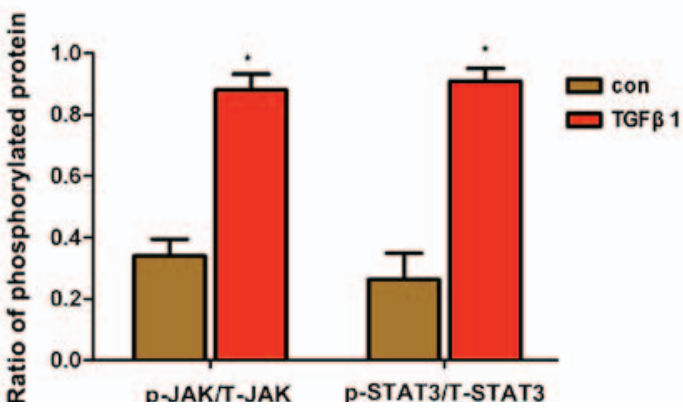

Figure 2. EMT induced by TGF $\beta 1$ in HepG2 cells. (A) TGF $\beta 1$ induced HepG2 cell scattering. Cells were incubated with $10 \mu \mathrm{M}$ TGF $\beta 1$ for 48 h. Representative images were captured at a magnification of x200 using an Eclipse TE2000-U inverted microscope. Scale bar, $10 \mu \mathrm{m}$. (B-D) qPCR and western blot analysis of EMT markers in HepG2 cells after treatment with $10 \mu \mathrm{M}$ TGF 31 for $48 \mathrm{~h}$. Data are presented as mean \pm standard deviation of 3 independent experiments. ${ }^{*} \mathrm{P}<0.05$ vs. control. (E and F) Western blot analysis revealed that TGF $\beta 1$ promoted the expression of JAK, p-JAK, STAT3, and p-STAT3. Data are presented as mean \pm standard deviation of three independent experiments. ${ }^{*} \mathrm{P}<0.05$ vs. control. TGF $\beta 1$, transforming growth factor $\beta 1$; con, control; EMT, epithelial-to-mesenchymal transition; qPCR, quantitative polymerase chain reaction; JAK, Janus kinase; STAT3, signal transducer and activator of transcription 3.

cells also increased in a concentration-dependent manner, with the most prominent effects observed at a concentration of $10 \mu \mathrm{M}$ (Fig. 1A and B). These results indicated that TGF $\beta 1$ induced HepG2 cell migration and invasion in a concentration-dependent manner. Hence, the concentration of $10 \mu \mathrm{M}$ was selected for all further mechanistic studies.

TGF $\beta 1$ induces EMT in HepG2 cells. TGF $\beta 1$ is a factor that promotes EMT in cancer cells, as previously reported $(7,8)$. EMT is an important mechanism of cancer cell invasion and metastasis. The downregulation of E-cadherin expression and the upregulation of vimentin and $\mathrm{N}$-cadherin expression are considered to be markers of EMT. In the present study, TGF $\beta 1$ also induced cell scattering (Fig. 2A), indicating that TGF $\beta 1$ induces EMT, thereby increasing the migration and invasion of HepG2 cells. To further investigate whether EMT is involved in TGF 31 -induced scattering, migration and invasion of HepG2 cells, the expression of E-cadherin, vimentin and $\mathrm{N}$-cadherin were first detected by qPCR and western blot analysis. As shown in Fig. $2 \mathrm{~B}$ and $\mathrm{C}$, the expression of vimentin and
$\mathrm{N}$-cadherin was upregulated, whereas that of E-cadherin was downregulated following treatment with $10 \mu \mathrm{M}$ TGF $\beta 1$. These results demonstrated that TGF $\beta 1$-induced EMT promoted the migration and invasion of HepG2 cells.

Moreover, JAK/STAT3 protein expression was detected by western blot analysis and it was observed that TGF $\beta 1$ stimulated the expression of p-JAK and p-STAT3. This finding indicates that TGF $\beta 1$-induced EMT may be activated by JAK/STAT3 signaling.

JAK/STAT3 signaling is involved in TGF $\beta 1$-induced EMT to increase migration and invasion of HepG2 cells. STAT3 is the key transcription factor regulating cell proliferation and survival. STAT3 may be activated by oncostatin $\mathrm{M}$, interferons, interleukin-6 (IL-6) and epidermal growth factor (EGF). It was recently reported that TGF $\beta 1$ induced JAK/STAT3 signaling to increase migration and invasion in lung carcinomacells. Based on these reports, we hypothesized that JAK/STAT3 signaling may be involved in TGF $\beta 1$-induced EMT to increase the migration and invasion in HepG2 cells. To confirm this hypothesis, HepG2 
A

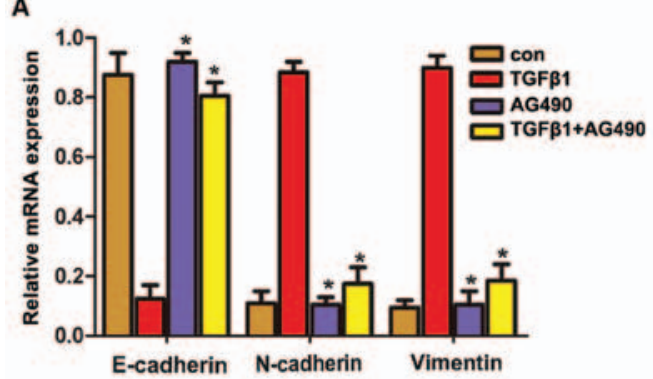

C

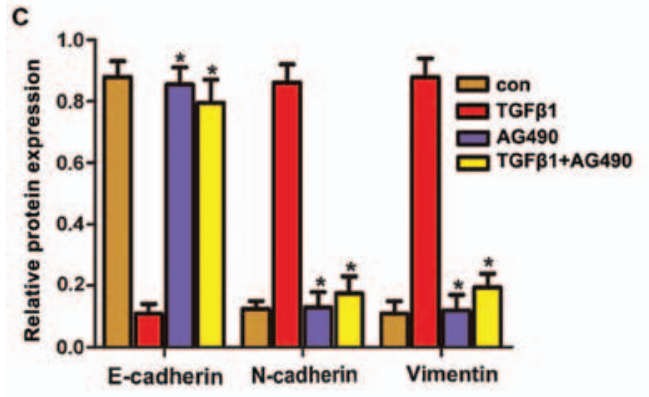

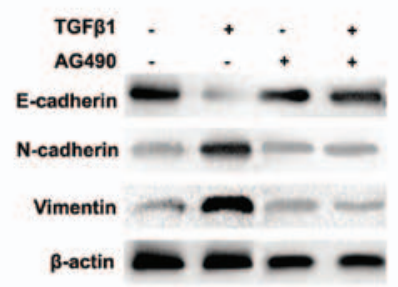

D

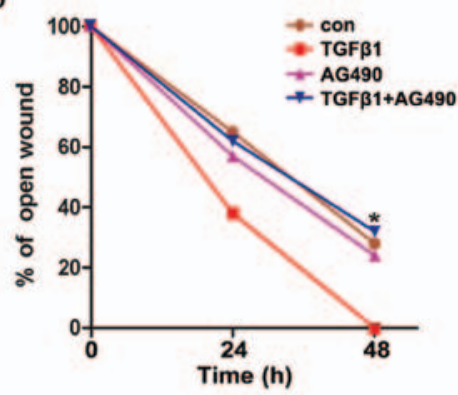

E
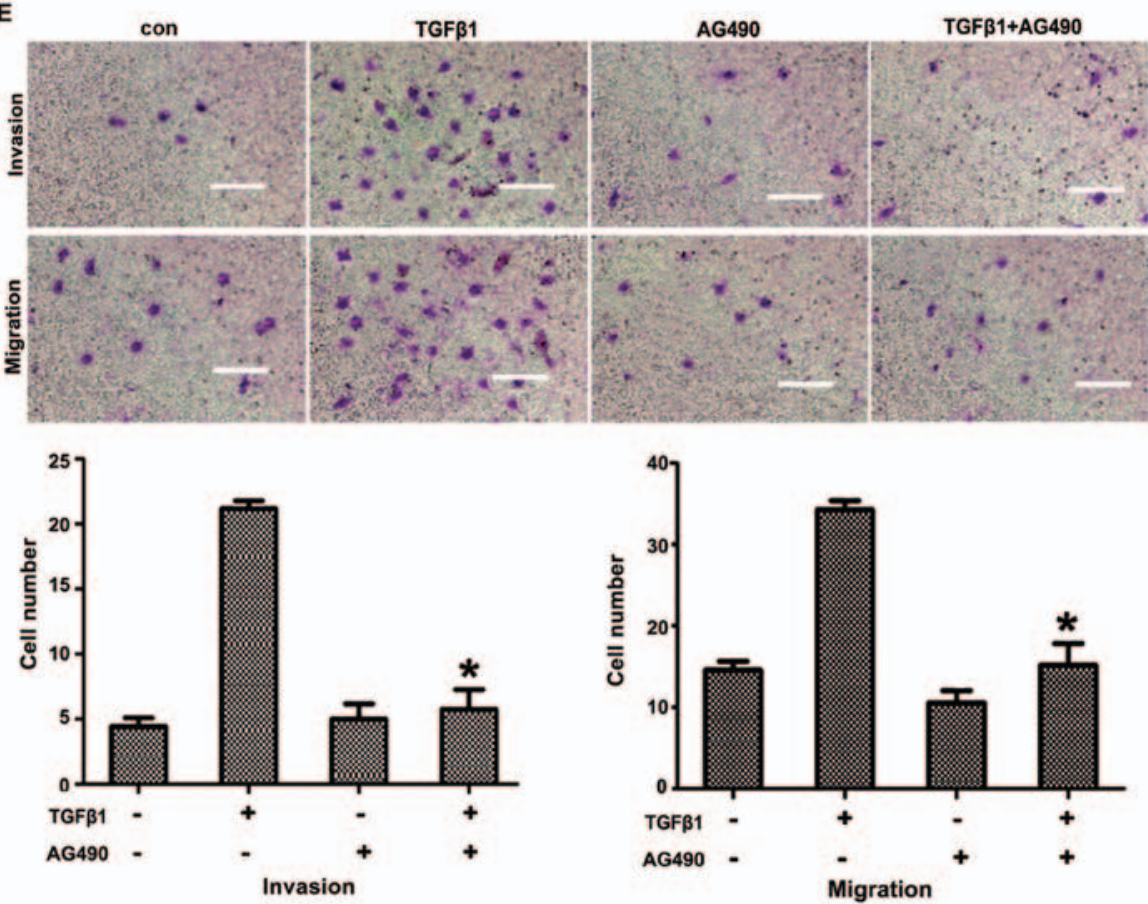

Figure 3. AG490 inhibits TGF $\beta 1$-induced EMT to increase migration and invasion via JAK/STAT3 signaling in HepG2 cells (A-C). Effects of TGF $\beta 1$ and AG490 on EMT-related protein expression in HepG2 cells. After the cells were treated with TGF $\beta 1$, AG490 and TGF $\beta 1$ + AG490 for 48 h, reverse transcription-quantitative polymerase chain reaction and western blot analysis of EMT markers in HepG2 cells were performed. Data are presented as mean \pm standard deviation of three independent experiments. " $\mathrm{P}<0.05$ vs. TGF $\beta 1$ group. (D) Wound-healing assay suggested that TGF $\beta 1$ markedly promoted cell motility. The promoting effects of TGF $\beta 1$ were abolished by AG490 treatment in HepG2 cells. The experiments were performed in triplicate. Data are presented as mean \pm standard deviation. "P<0.05 vs. TGF $\beta 1$ group. (E) AG490 inhibited TGF $\beta 1$ to promote migration and invasion in HepG2 cells. In migration and invasion assays, cells were treated with TGF $\beta 1$, AG490 and TGF $\beta 1$ + AG490 for $48 \mathrm{~h}$. The promoting effects of TGF $\beta 1$ were abolished by AG490 treatment in the HepG2 cells. Cells were visualized by staining with toluidine blue and counted in six random high-power fields at a magnification of x 200 using Image-Pro ${ }^{\circledR}$ Express software. Scale bar, $10 \mu \mathrm{m}$. The experiments were performed in triplicate. Data are presented as mean \pm standard deviation. ${ }^{*} \mathrm{P}<0.05 \mathrm{vs}$. TGF $\beta 1$ group. TGF $\beta 1$, transforming growth factor $\beta 1$; con, control; EMT, epithelial-to-mesenchymal transition; JAK, Janus kinase; STAT3, signal transducer and activator of transcription 3.

cells were incubated with the STAT3 inhibitor AG490 prior to treatment with TGF 31 . As shown in Fig. 3A and C, AG490 significantly suppressed the TGF $\beta 1$-induced upregulation of $\mathrm{N}$-cadherin and vimentin expression and the downregulation of E-cadherin expression, compared with the TGF $\beta 1$ group. Furthermore, AG490 treatment significantly reduced the number of TGF $\beta 1$-induced invasive and migratory cells (Fig. 3E and F), which was consistent with the results obtained from metastasized cell-wound closure (Fig. 3D).

Twist is involved in TGF 1 -induced EMT depending on STAT3. Smad 2 and Twist are important factors regulating EMT through 
A

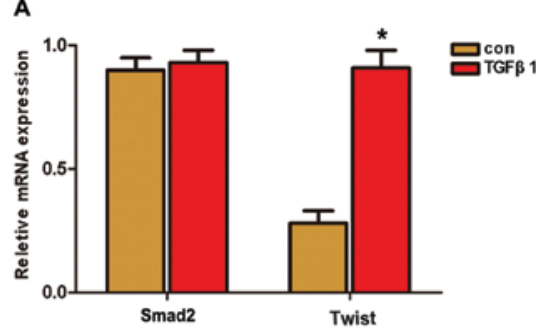

C

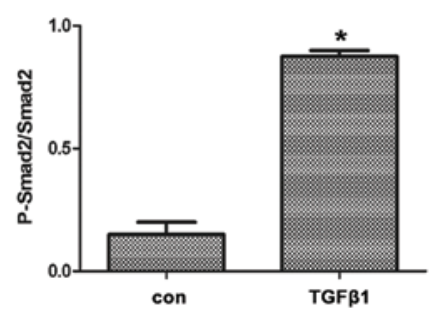

E
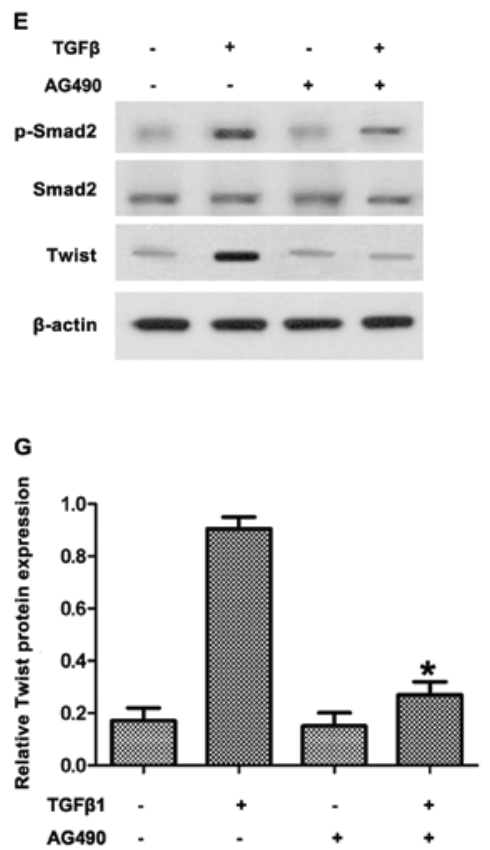

B

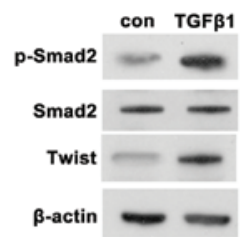

D

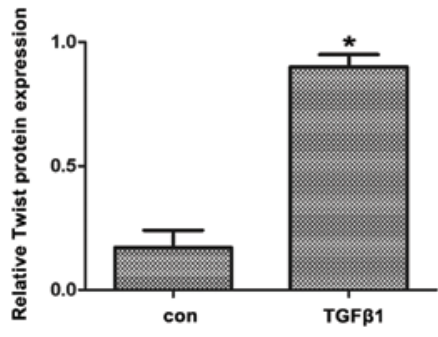

$\mathbf{F}$

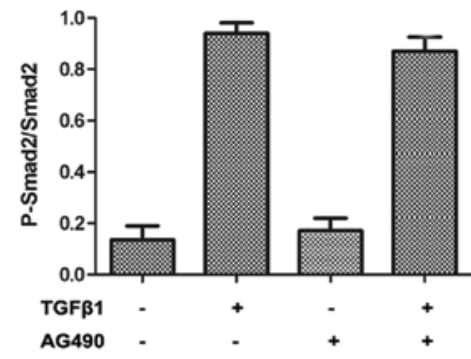

Figure 4. (A-D) AG490 inhibited TGF $\beta 1$-induced expression of Twist and p-Smad2 in HepG2 cells. The effects of TGF $\beta 1$ on the expression of p-Smad2 and Twist in HepG2 cells were investigated by incubating HepG2 cells with $10 \mu \mathrm{M}$ TGF $\beta 1$ for $48 \mathrm{~h}$, followed by reverse transcription-quantitative polymerase chain reaction and western blot analysis of Smad2 and Twist expression. (E-G) The expression of p-Smad2 was analyzed by western blot analysis; AG490 inhibited the TGF $\beta 1$-induced expression of Twist and p-Smad2 in HepG2 cells. The cells were pretreated with AG490 for $2 \mathrm{~h}$ and then incubated with or without TGF $\beta 1$ $(10 \mu \mathrm{M})$ for $48 \mathrm{~h}$, followed by western blot analysis of $\mathrm{p}-\mathrm{Smad} 2$, Smad2 and Twist expression. The experiments were performed in triplicate. Data are presented as mean \pm standard deviation. "P<0.05 vs. TGF $\beta 1$ group. TGF $\beta 1$, transforming growth factor $\beta 1$; EMT, epithelial-to-mesenchymal transition.

TGF $\beta 1$. Thus, we hypothesized that TGF $\beta 1$ induced EMT by upregulating Twist expression via JAK/STAT3 signaling. To confirm this hypothesis, the expression of pSmad2 and Twist in HepG2 cells treated with TGF $\beta 1$ was first detected. The results revealed that TGF $\beta 1$ induced the protein expression of pSmad 2 and Twist (Fig. 4A-D). By contrast, AG490 treatment reversed the TGF $\beta 1$-induced protein expression of $\mathrm{pSmad} 2$ and Twist (Fig. 4E-G). Along these lines, TGF $\beta 1$ induced the protein expression of $\mathrm{pSmad} 2$ and Twist in accordance with the activated JAK/STAT3 signaling.

To further determine whether Twist participated in TGF $\beta 1$-induced EMT, HepG2 cells were transfected with siRNA of Twist. As shown in Fig. 5A-C, Twist knockdown significantly suppressed the TGF $\beta 1$-induced expression of
$\mathrm{N}$-cadherin and vimentin, but reversed the TGF $\beta 1$-inhibited expression of E-cadherin. The TGF $\beta 1$-induced migration and invasion in HepG2 cells were also reversed through Twist knockdown. Overall, these data strongly suggest that Twist participates in TGF $\beta 1$-induced EMT to increase the migration and invasion of HepG2 cells via JAK/STAT3 signaling.

\section{Discussion}

Invasion and metastasis are the leading causes of death from liver cancer (12). The onset and progression of liver cancer are regulated and controlled by various factors, among which EMT is the key mechanism promoting invasion and metastasis (13). A number of studies demonstrated that molecular markers are 


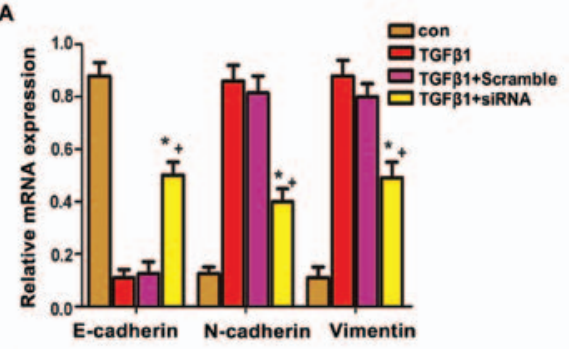

C

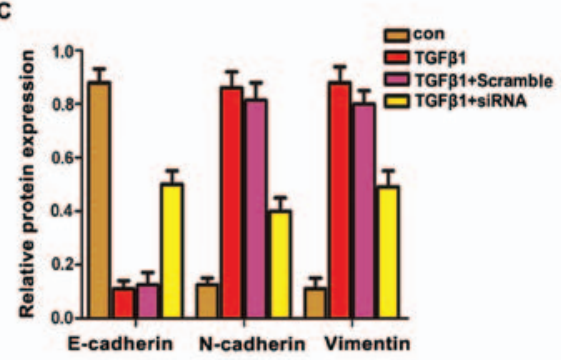

B

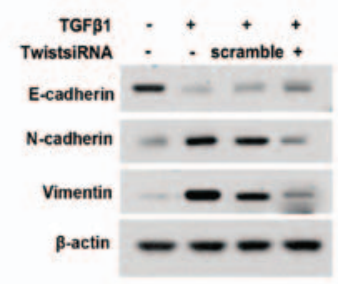

D

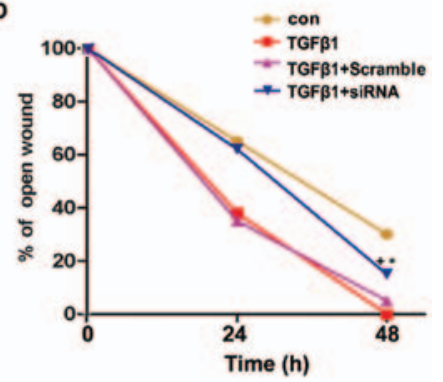

$\mathbf{E}$
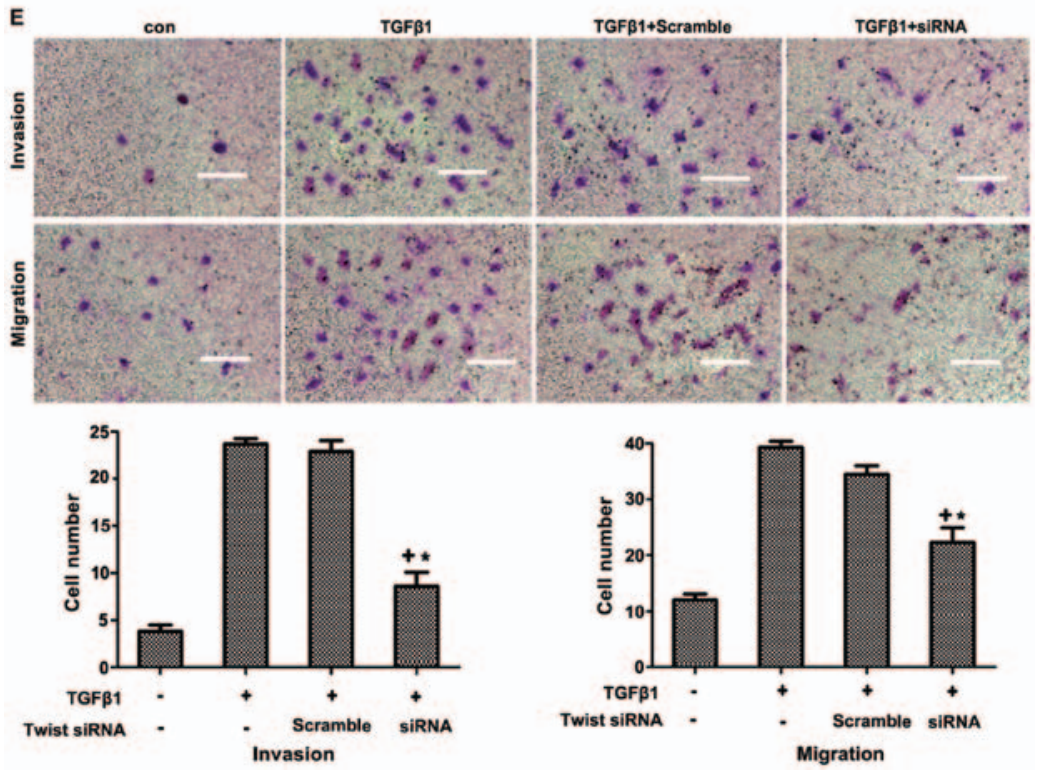

Figure 5. (A-C) Twist siRNA blocked the TGF 31 -induced EMT-mediated increase in the migration and invasion of HepG2 cells. Twist siRNA blocked the TGF $\beta 1$-induced EMT-related protein expression. HepG2 cells were pretreated with Twist siRNA for $12 \mathrm{~h}$ and then incubated with or without TGF $\beta 1$ ( $10 \mu \mathrm{M})$ for $48 \mathrm{~h}$. E-cadherin, $\mathrm{N}$-cadherin and vimentin proteins were analyzed by western blotting. (D) Wound-healing assay revealed that TGF $\beta 1$ markedly promoted cell motility. The promoting effects of TGF $\beta 1$ were abolished by Twist siRNA treatment in HepG2 cells. (E) Twist siRNA blocked TGF $\beta 1$-induced migration and invasion in HepG2 cells. HepG2 Cells were pretreated with Twist siRNA for $12 \mathrm{~h}$ and then incubated with or without TGF $\beta 1$ (10 $\mu \mathrm{M}$ ) for $48 \mathrm{~h}$. Cells were visualized by staining with toluidine blue and counted in six random high-power fields at a magnification of x 200 by using Image-Pro ${ }^{\circledR}$ Express software. Scale bar, $10 \mu \mathrm{m}$. The experiments were performed in triplicate. Data are presented as mean \pm standard deviation. "P<0.05 vs. TGF $\beta 1$ group. TGF $\beta 1$, transforming growth factor $\beta 1$; con, control; EMT, epithelial-to-mesenchymal transition.

altered during EMT in cancer cells; for example, E-cadherin (an epithelial marker) and ZO-1 (a closely connected protein) are downregulated, whereas the levels of molecular markers derived from interstitial cells, including vimentin and $\mathrm{N}$-cadherin, are upregulated. Hence, adhesions among tumor cells are reduced, thereby increasing the invasion and metastasis of cancer cells (14-16). The occurrence of EMT is affected by various factors. TGF $\beta 1$ is a key factor that induces and participates in the entire process of EMT (17-19). In the present study, TGF $\beta 1$ was found to upregulate vimentin and downregulate E-cadherin expression. Moreover, TGF $\beta 1$ induced scattering, invasion and metastasis of HepG2 cells. These results demonstrated that TGF $\beta 1$-induced EMT, thereby promoting the invasion and metastasis of HepG2 cells.
STAT3 is a signal transduction and transcription activator. Abnormal regulation of the STAT3 signaling pathway is associated with tumor occurrence and development (20). Following activation by cytokines or growth factors, the activated JAK may collect STAT3 monomers to produce homologous or heterogonous dimers; subsequently, nuclei and specific DNA sequences regulate the transcription of target genes (21). The abnormal expression and activation of STAT3 in various tumor tissues and cell lines (including liver cancer cells) are associated with the invasion and metastasis of tumor cells (21). EMT is the first focus in studies investigating the invasion and metastasis of tumor cells. The activation of the STAT3 signaling pathway is associated with EMT, invasion and metastasis of tumors. Colomiere et al (22) demonstrated 
that the JAK/STAT3 pathway is aberrantly activated in ovarian cancer tissues. Furthermore, EMT in ovarian cancer cells may be induced by EGF or IL-6 $(23,24)$. These results indicated that the action of EGF or IL- 6 relies on the activation of JAK/STAT3 signaling; EMT induced by EGF or IL-6 may be significantly inhibited by treatment with the JAK/STAT3 pathway inhibitor AG490, and the invasion and metastasis of ovarian cancer cells may be reduced. Xiong et al (25) also reported that AG490 significantly suppressed STAT3 activation; consequently, AG490 treatment upregulated E-cadherin expression but reduced the invasion of tumor cells in colorectal cancer. In the present study, the JAK/STAT3 pathway was activated when the TGF $\beta 1$-induced EMT promoted the migration and invasion of HepG 2 cells, whereas AG490 reversed these effects. Overall, the results demonstrated that TGF $\beta 1$-induced EMT was inhibited, thereby confirming the involvement of the JAK/STAT3 pathway in EMT induction.

Lee et al (7) reported that JAK/STAT3 pathway activation promotes the expression of Twist and, thus, reduces the EMT of breast cancer cells. Cheng et al (17) also reported that the activated STAT3 may directly bind to the STAT3 binding site of the Twist promoter in breast cancer cells. These studies support that STAT3 activation may regulate the expression of Twist, a key transcription factor regulating EMT. In the present study, Twist was downstream from the JAK/STAT3 pathway in HepG2 cells; thus, AG490 treatment was applied for $2 \mathrm{~h}$ prior to incubation with TGF $\beta 1$. Our results demonstrated that the expression of Twist was inhibited by AG490. Overall, TGF $\beta 1$ induced the expression of Twist in accordance with the JAK/STAT3 pathway activation. Furthermore, we observed that Twist participated in the TGF 31 -induced EMT that promoted invasion and metastasis in HepG2 cells. This finding is consistent with the report of Liu et al (26). Thus, these results indicated that TGF $\beta 1$ upregulated the expression of Twist via the JAK/STAT3 pathway, thereby promoting the invasion and metastasis of HepG 2 cells.

The findings of the present study verified the biological functions of TGF $\beta 1$ in liver cancer HepG2 cells and provided evidence that the TGF $\beta 1$-induced EMT promoted the invasion and metastasis of HepG2 cells in vitro. It was further demonstrated that these actions may be mediated via the JAK/STAT3/Twist signaling pathway. In conclusion, TGF $\beta 1$ appears to be involved in the progression of liver cancer and represents a potential molecular target for the treatment of this disease.

\section{Acknowledgements}

This study was supported by the Natural Science Foundation of China (grant no. 81600342), the Medical Foundation of Hui Zhou (grant no. 2015Y134); the Medical Research Foundation of Guangdong Province (grant no. A2015620); and the Graduate Student Research Innovation Project of Hunan Province (grant no. CX2013B396).

\section{References}

1. Jemal A, Bray F, Center MM, Ferlay J, Ward E and Forman D Global cancer statistics. CA Cancer J Clin 61: 69-90, 2011.

2. Huang HC, Hu CH, Tang MC, Wang WS, Chen PM and Su Y: Thymosin beta4 triggers an epithelial-mesenchymal transition in colorectal carcinoma by upregulating integrin-linked kinase. Oncogene 26: 2781-2790, 2007.
3. Gjerdrum C, Tiron C, Høiby T, Stefansson I, Haugen H, Sandal T, Collett K, Li S, McCormack E, Gjertsen BT, et al: Axl is an essential epithelial-to-mesenchymal transition-induced regulator of breast cancer metastasis and patient survival. Proc Natl Acad Sci USA 107: 1124-1129, 2010.

4. Song Y, Washington MK and Crawford HC: Loss of FOXA1/2 is essential for the epithelial-to-mesenchymal transition in pancreatic cancer. Cancer Res 70: 2115-2125, 2010.

5. Lee TK, Poon RT, Yuen AP, Ling MT, Kwok WK, Wang XH, Wong YC, Guan XY, Man K, Chau KL, et al: Twist overexpression correlates with hepatocellular carcinoma metastasis through induction of epithelial-mesenchymal transition. Clin Cancer Res 12: 5369-5376, 2006.

6. Giannelli G, Fransvea E, Bergamini C, Marinosci F and Antonaci S: Laminin-5 chains are expressed differentially in metastatic and nonmetastatic hepatocellular carcinoma. Clin Cancer Res 9: 3684-3691, 2003.

7. Lee J, Choi JH and Joo CK: TGF- $\beta 1$ regulates cell fate during epithelial-mesenchymal transition by upregulating survivin. Cell Death Dis 4: e714, 2013

8. O'Connor JW and Gomez EW: Cell adhesion and shape regulate TGF-beta1-induced epithelial-myofibroblast transition via MRTF-A signaling. PLoS One 8: e83188, 2013.

9. Wendt MK, Balanis N, Carlin CR and Schiemann WP: STAT3 and epithelial-mesenchymal transitions in carcinomas. JAK-STAT 3: e28975, 2014.

10. Kamran MZ, Patil P, Gude RP. Role of STAT3 in cancer metastasis and translational advances. Biomed Res Int. 2013: 421821, 2013.

11. Hills CE and Squires PE: The role of TGF- $\beta$ and epithelial-to mesenchymal transition in diabetic nephropathy. Cytokine Growth Factor Rev 22: 131-139, 2011.

12. Ksiażkiewicz M, Markiewicz A and Zaczek AJ : Epithelial-mesenchymal transition: A hallmark in metastasis formation linking circulating tumor cells and cancer stem cells. Pathobiology 79: 195-208, 2012.

13. Levy DE, Darnell JE Jr: Stats: transcriptional control and biological irnpact. Nat Rev Mol Cell Biol 3: 651-662, 2002.

14. Wu Y, Sarkissyan M and Vadgama JV: Epithelial-Mesenchymal Transition and Breast Cancer. J Clin Med 5: 2-18, 2016.

15. Brivio S, Cadamuro M, Fabris L and Strazzabosco M. Epithelial-to-mesenchymal transition and cancer invasiveness: What can we learn from cholangiocarcinoma? J Clin Med 4: 2028-2041, 2015.

16. Nalluri SM, O'Connor JW and Gomez EW: Cytoskeletal signaling in TGF 3 -induced epithelial-mesenchymal transition. Cytoskeleton 72: 557-569, 2015.

17. Cheng GZ, Zhang WZ, Sun M, Wang Q, Coppola D, Mansour M, Xu LM, Costanzo C, Cheng JQ and Wang LH: Twist is transcriptionally induced by activation of STAT3 and mediates STAT3 oncogenic function. J Biol Chem 283: 14665-14673, 2008.

18. Zhang S, Sun WY, Wu JJ, Gu YJ and Wei W: Decreased expression of the type III TGF- $\beta$ receptor enhances metastasis and invasion in hepatocellullar carcinoma progression. Oncol Rep 35: 2373-2381, 2016

19. Yeh YH, Wang SW, Yeh YC, Hsiao HF and Li TK: Rhapontigenin inhibits TGF- $\beta$-mediated epithelial mesenchymal transition via the PI3K/AKT/mTOR pathway and is not associated with HIF-1a degradation. Oncol Rep 35: 2887-2895, 2016.

20. Piccirillo R and Giavazzi R: Inactivating STAT3: Bad for tumor, good for muscle. Cell Cycle 14: 939-940, 2015.

21. Wake MS and Watson CJ: STAT3 the oncogene - still eluding therapy? FEBS J 282: 2600-2611, 2015.

22. Colomiere M, Ward AC, Riley C, Trenerry MK, Cameron-Smith D, Findlay J, Ackland L and Ahmed N: Cross talk of signals between EGFR and IL-6R through JAK2/STAT3 mediate epithelial-mesenchymal transition in ovarian carcinomas. Br J Cancer 100: 134-144, 2009.

23. Li CJ, Li YC, Zhang DR and Pan JH: Signal transducers and activators of transcription 3 function in lung cancer. J Cancer Res Ther 9 (Suppl 2): S67-S73, 2013.

24. Liu A,Zhao F, Wang J,Zhao Y, Luo Z, Gao Y and Shi J: Regulation of TRPM7 function by IL-6 through the JAK2-STAT3 signaling pathway. PLoS One 11: e0152120-e0152132, 2016

25. Xiong H, Zhang ZG, Tian XQ, Sun DF, Liang QC, Zhang YJ, Lu R, Chen YX and Fang JY: Inhibition of JAK1, 2/STAT3 signaling induces apoptosis, cell cycle arrest, and reduces tumor cell invasion in colorectal cancer cells. Neoplasia 10: 287-297, 2008.

26. Liu RY, Zeng Y, Lei Z, Wang L, Yang H, Liu Z, Zhao J and Zhang HT: JAK/STAT3 signaling is required for TGF- $\beta$-induced epithelial-mesenchymal transition in lung cancer cells. Int $\mathbf{J}$ Oncol 44: 1643-1651, 2014.

This work is licensed under a Creative Commons Attribution-NonCommercial-NoDerivatives 4.0 International (CC BY-NC-ND 4.0) License. 